\title{
19 Bird Damage to Rice in Africa: Evidence and Control
}

\author{
Yann de Mey ${ }^{1}$ and Matty Demont ${ }^{2 *}$ \\ ${ }^{1}$ Hasselt University, Centre for Environmental Sciences, \\ Diepenbeek, Belgium; ${ }^{2}$ Africa Rice Center, Saint-Louis, Senegal
}

\section{Introduction}

Rice, one of the most important cereal crops worldwide, has the potential to play a significant role in achieving global food security. However, several biotic and abiotic stresses seriously jeopardize this potential. According to Oerke (2005), some $15 \%$ of global rice production is lost to animal pests (arthropods, nematodes, rodents, birds, slugs and snails). The Global Rice Science Partnership (GRiSP) identifies birds as the second most important biotic constraint in African rice production after weeds, based on farmer surveys in 20 African countries (IRRI et al., 2010). Despite current control practices, birds cause substantial losses to the African rice sector. Diagne et al. (chapter 32, this volume) provide an ex-ante assessment of the benefits of rice research. They indicate discounted cumulative benefits of $\$ 254.0$ million for research aimed at reducing yield loss to birds and rodents, and $\$ 4.271$ billion for total benefit derived from the research agenda - thus, the contribution of research on reducing losses to birds and rodents comprises $5.95 \%$ of the total benefit of the whole research agenda.

Rice is mainly affected by birds in the humid zone and, to various degrees, in the Sahel and Sudanian savannah zones (Manikowski, 1984;
FAO, 1991). The most serious pest birds are gregarious and migratory, such as Red-billed Quelea, but locally other types such as water birds (e.g. ducks and geese) can also be of importance. Rice crops are vulnerable to bird attacks at early crop establishment stages (mostly by water birds) and highly susceptible from the milky stage up to maturation (exclusively by land birds). Most damage occurs during the dry season; in the rainy season there is usually an abundance of seeds from wild grasses available as alternative food sources (Ruelle and Bruggers, 1982).

Aside from physical yield losses - which are the main focus of this chapter - other problems caused by pest birds include extensive labour requirements for bird scaring, the associated use of child labour, possible health or environmental hazards resulting from the use of chemical poisons, and the discouragement of farmers from dry-season rice cultivation.

Although the adverse impact of birds on rice has received much international attention in the past and is still generally recognized, little research on bird damage or control is currently conducted. Given the increasing importance of bird damage in some regions such as the Sahel (de Mey, 2009), this chapter reviews the available evidence of bird damage to rice in Africa, the

* Corresponding author: m.demont@irri.org 
bird species involved, and the measures commonly used to control them.

\section{Pest Bird Species Injurious to Cereal Crops in Africa}

On a global scale, only a handful of birds are serious pests of cereal crops. Birds can become serious pests when large flocks migrate seasonally and concentrate in large populations. In a review of literature, Manikowski (1984) lists 36 bird species as 'known to cause damage' among the approximately 1390 bird species in West Africa (van Perlo, 2002). The seven most important species are Spur-winged Goose (Plectropterus gambensis), Knob-billed Goose (Sarkidiornis melanotos), Village Weaver (Ploceus cucullatus), Black-headed Weaver (Ploceus melanocephalus), Red-billed Quelea (Quelea quelea), Red-headed Quelea (Q. erythrops) and Golden Sparrow (Passer luteus). More background information on granivorous pest birds in sub-Saharan Africa (their identification, biology and feeding habits) is provided by Allen (1997).

Red-billed Quelea is one of the most notorious pest bird species in the world, injurious to various cereal crops such as rice, millet, sorghum and wheat (FAO, 1991). It occurs throughout sub-Saharan Africa. It gathers in flocks of several million birds and breeds in colonies that can cover more than 100 hectares (with about 30,000 nests per hectare). It is considered the most numerous bird worldwide with population numbers totalling about 1.5 billion at the end of the breeding season (Elliott, 1989). Red-billed Quelea has been studied extensively and there are many publications describing its pest status and control strategies in African agriculture (see Oschadleus, 2001).

\section{Evidence of Bird Damage to Rice in Africa}

\section{Factors influencing bird damage}

Birds differ in nature to many other pests of rice in that they can migrate over long distances and have a flexible diet in which agricultural crops may play only an incidental role (birds prefer wild seeds, see below). Great variability exists in the occurrence and extent of the crop damage due to birds that farmers experience (in both space and time) due to many biological, environmental and management factors (described below).

Fields close to breeding or roosting sites are most susceptible to damage from birds (FAO, 1991). The presence of trees, bushes or reeds in the vicinity of the field increases vulnerability because these provide birds with perches and nesting sites. Fields close to water sources (e.g. rivers or large irrigation canals) are more frequently damaged by birds because - as a supply of drinking water - they attract birds (Manikowski, 1984) and provide habitats for water birds such as geese that are potentially harmful to rice. These factors in the immediate surroundings of rice fields vary spatially, which makes bird damage a region-dependent problem with some regions having serious bird problems, while others experience almost no bird attacks at all. Furthermore, as birds are migratory the problem needs to be managed cooperatively between neighbouring countries.

Field size influences bird damage. Large fields have longer borders (in absolute terms) which are the zones preferentially attacked by birds. Moreover, a large field requires a large labour force for bird scaring, which is particularly challenging to assemble during peak periods (Manikowski and Da Camara-Smeets, 1979).

The timing of farming operations during the season is a crucial factor that can influence the incidence of bird damage. Sowing too late during the wet season predisposes the crop to damage by migrating birds from Europe arriving at the time when the crop matures (Tréca, 1985). Therefore, synchronized cropping among farmers may dilute bird-inflicted losses to some extent. Damage is expected to be higher during the dry season than during the wet season due to the lack of available wild seeds (Ruelle and Bruggers, 1982). Damage also differs with respect to the growth stage of the rice crop (Tréca, 1977). Rice is susceptible to bird damage at the early crop establishment stages (see discussion below), but subsequently invulnerable during the vegetative and booting stages. Throughout maturation (milk to hard-dough stages) the rice crop is highly susceptible to bird damage (Ruelle and Bruggers, 1982). Postharvest losses can also occur during drying, storage or trading because at these stages 
the rice grains are frequently left exposed in the open. This is particularly true during drying, which is carried out by simply laying the rice grains on a sheet in the sun.

The effectiveness of weed control in a field and on the banks of irrigation canals plays an indirect role in bird damage as weedy fields attract birds. The bulk of the diet of Red-billed Quelea does not consist of cultivated cereals; they prefer smaller seeds of various wild grasses (Ward, 1965). This implies that if these wild grasses are widely available in or near a farmer's fields, bird flocks will be attracted to that area and occasionally feed on the cereal crops. This way, the birds become familiar with the region and will return for feeding purposes. A study on wheat showed that weedy patches in fields are clearly associated with greater bird damage (Luder, 1985) and several studies on rice cite the same interaction between weeds and birds (e.g. Bruggers, 1979; Tréca, 1985; FAO, 1991). A survey in the Senegal River valley revealed that almost $80 \%$ of rice farmers were aware of the interaction between weeds and birds, and 57\% plan their weeding efforts in relation to bird pressure (de Mey, 2009). This is confirmed by a field trial conducted by Africa Rice Center (AfricaRice), which concludes that weed control reduces bird damage in irrigated rice (Rodenburg et al., 2010). Weeds infesting rice fields attract granivorous birds, which leads to increased crop losses due to the effects of weed competition being compounded by the losses to birds.

Bird damage is also affected by the crop establishment method (Tréca, 1977). In the case of direct seeding, seeds are highly vulnerable to bird attack when they are sown straight on to the soil. A common practice, however, is to cover seeds with soil to protect them. Young, emerging seedlings are still vulnerable to birds; however, damage at this stage is rare during the rainy season when most granivorous migratory birds have flown to Europe and Asia (Tréca, 1977). On the other hand, if farmers transplant rice, the vulnerability of freshly sown rice seeds in the nursery bed to bird attacks can be greatly reduced by protecting the nurseries with nets. Planting density in the field is also an important factor. Uneven crop plant densities can result from improper sowing or planting, a badly levelled field or other factors leading to heterogeneous field conditions. Water birds are attracted to zones with plant densities much lower than in the immediate vicinity and can cause substantial damage to the surrounding rice plants (Tréca, 1977). The choice of rice variety also affects damage as birds have a preference for particular varieties and will completely ignore others (e.g. awned varieties) if sufficient alternative food sources are available. Varieties with weak stems are also more susceptible to mechanical damage if they cannot support the birds' weight (FAO, 1991).

As mentioned above, birds prefer seeds of wild grass species. As soon as these natural grain stocks start to decline at the end of the rainy season, Red-billed Queleas gather in inundation zones where wild seed production is greatest. Once these natural reserves of grains are exhausted and at the onset of the next rains (which cause the remaining seeds to start geminating - hence making them unavailable as a food source) the pest birds are threatened with starvation. This forces the birds into a nomadic migration to areas where the rains came earlier and where fresh crop and weed seeds are available in abundance. These huge flocks of birds are feared by farmers because they consist of large numbers of starving birds which see rice fields as oases of food abundance in an otherwise foodscarce landscape (Ward, 1971; Jones, 1989). Given the unpredictable nature of rainfall patterns, Red-billed Quelea movement patterns are difficult to predict. General trends show, however, that damage tends to be less severe in years of high rainfall, which probably relates to the availability of seeds of wild species as explained above (Bruggers, 1980). Life cycle is another biological factor, as, for example, young Redbilled Queleas will inflict damage in the immediate vicinity of the roosts, whereas mature individuals will fly out and cause damage further away. Feeding behaviour of different bird species varies with time of the day and the maturation stage of the rice crop (Bruggers, 1979). The presence of some (grain-eating) birds in a field can also attract others (FAO, 2001).

\section{Review of the available evidence}

Birds cause visual damage patterns to the rice crop such as: (i) direct damage when seeds or 
grains are eaten by birds; and (ii) indirect (mechanical) damage that occurs when a flock of birds is active in a rice field, resulting in grains that fall to the ground (Tréca, 1987). Both are important and should be taken into account when assessing bird damage.

There are many direct and indirect techniques to assess crop losses due to birds. Direct measures include field sampling and visual estimation techniques. The former is based on the counting or weighing of a representative sample of rice panicles (e.g. Bruggers and Ruelle, 1981), while the latter comprises experienced observers estimating losses by visual inspection of a field (e.g. Tracey and Saunders, 2010). Frequently, sampling techniques are also used to calibrate visual assessments. Due to the heterogeneity of the bird problem, however, large sample sizes are needed across several production seasons, which renders these methods labour intensive and expensive. Indirect methods include questionnaire surveys, monitoring of bird numbers, energetics models, and damage-abatement models. While questionnaire surveys are obviously subjective, they do serve to demonstrate the general levels of damage and the relative seriousness of the problem according to farmers' perceptions (e.g. Sidibé et al., 2003). Monitoring bird numbers enables the species involved and its behaviour to be determined, which, in turn, enhances the understanding of the bird problem (e.g. Bruggers, 1980). Estimating bird damage is based on using the correlation between bird density and damage - a relationship that is (unfortunately) rarely known and difficult to obtain. Energetics models are more advanced models that take pest-bird population estimates and make use of the determinants of energy requirement of these populations (e.g. age, temperature and body weight) to predict the amount of damage they will inflict (e.g. Weatherhead et al., 1982). de Mey et al. (2012) propose an indirect method relying on a production function with a damage-abatement component that enables bird damage to be econometrically isolated from overall rice crop productivity.

The latest extensive overview of world bird damage problems is provided by De Grazio (1978). Aggregating results of 32 studies (reporting damage in 626 plots), Manikowski (1984) suggests an average loss of $6.9 \%$ of cereal harvest in West Africa. The highest damage figures were found for millet in the Sahel zone $(25 \%)$ and rice in the humid zone (19\%). No more recent overviews are available. Table 19.1 provides a non-exhaustive literature overview and shows that bird damage is an important loss factor for cereal crop production in Africa. Table 19.1 suggests that bird damage on cereal crops is on average about $15-20 \%$ of production, but considerable spatial and temporal variability exists. Much research on bird damage on cereal crops was carried out by international research organizations prior to the 1980 s, e.g. the FAO/UNDP Quelea Project (Jackson, 1973), but subsequently few studies have been conducted. Furthermore, much material is only available in internal documents or unpublished research reports; recent, peer-reviewed damage estimates are scarce.

\section{Control of Bird Damage to Rice in Africa}

Many techniques are available to protect crops from bird damage. A literature review of the effectiveness of existing bird control techniques is provided by Bishop et al. (2003). The main conclusions of this study are that the effectiveness of each technique varies with the bird species involved, and that optimal bird control methods combine several techniques or use them in a random fashion. Human-operated scaring techniques were the most effective; lethal methods are of only short-term benefit. In Africa, traditional, low-cost methods are mainly used. Two general classes of approaches can be distinguished. Preventive methods aim at not attracting birds to the field, while protective methods focus on protecting the rice crop when birds do visit the field. Preventive methods can be subdivided into lethal and non-lethal techniques. Lethal techniques are aimed at suppressing pest bird populations and are primarily implemented by national or regional (governmental) crop protection units. They include manual nest destruction, treatment with avicides (chemical substances lethal to certain bird species) and the use of explosives or flamethrowers. Non-lethal techniques include agronomic practices such as vegetation management, good weed management (as weeds attract birds), specific planning of the production season and choosing a variety 


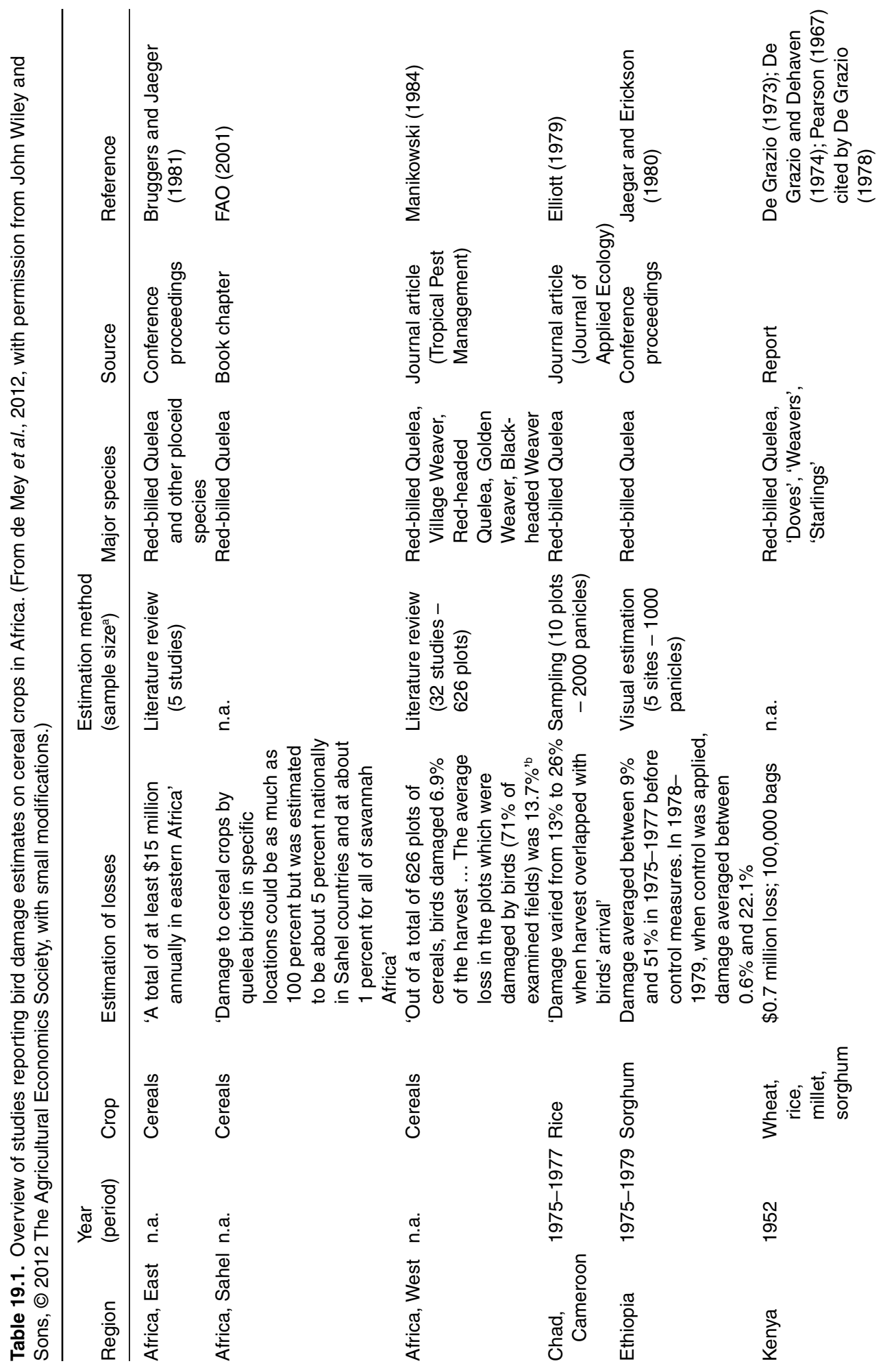



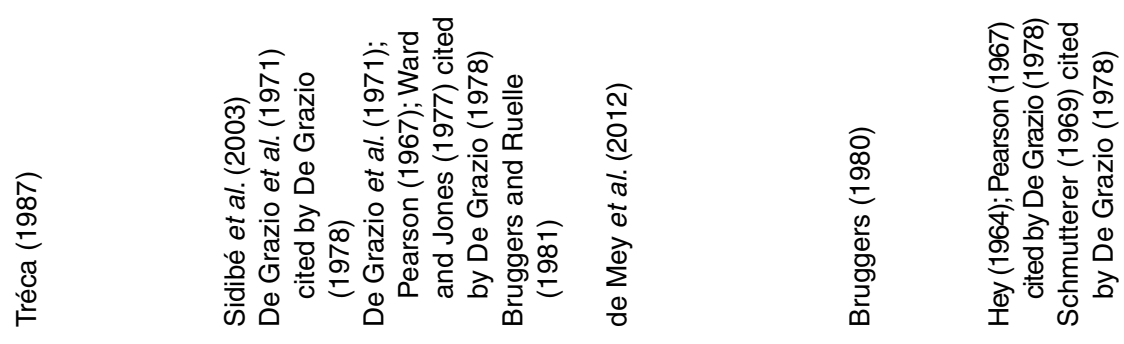

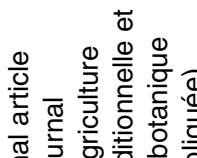

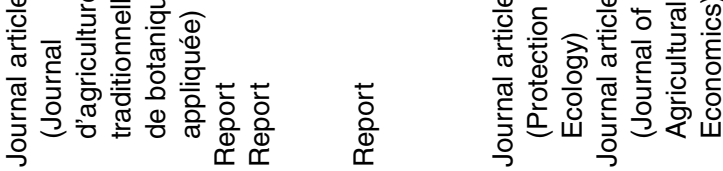
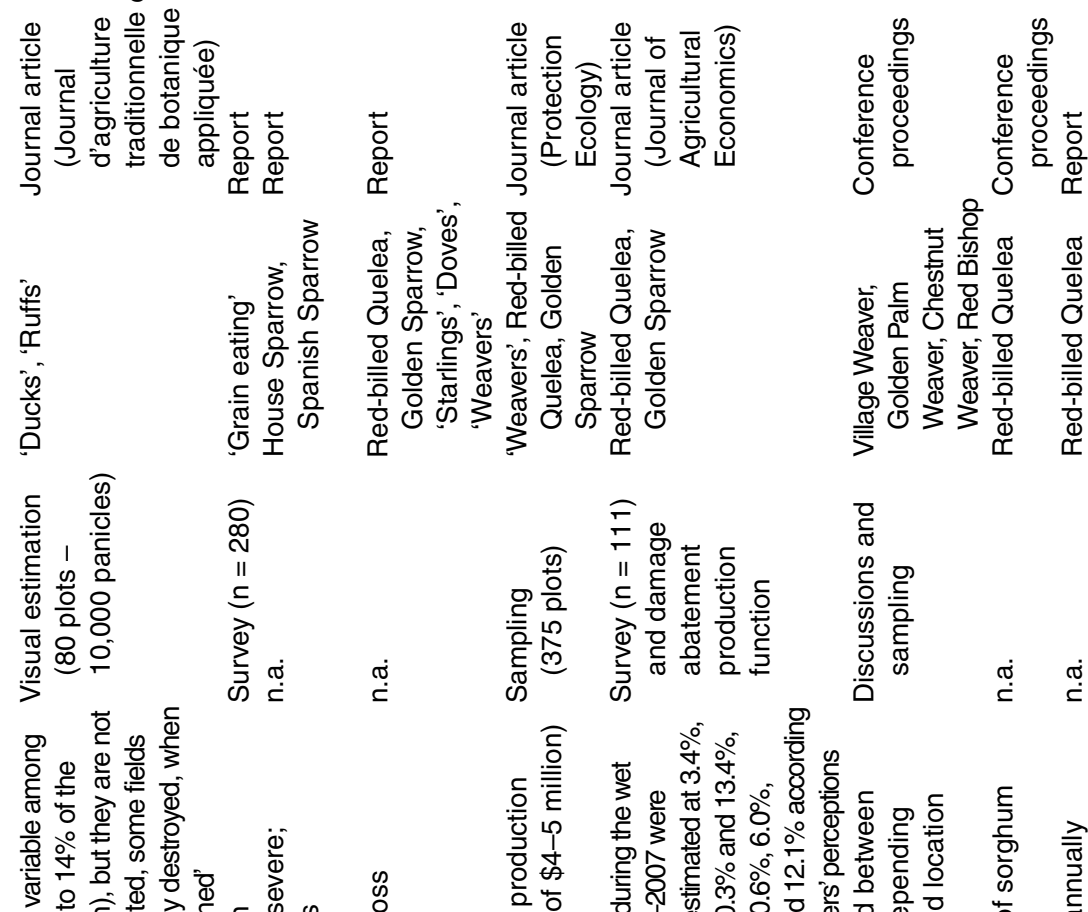

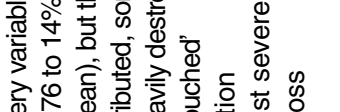

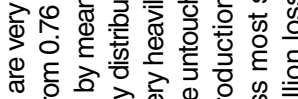

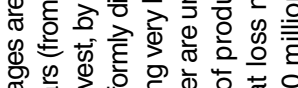

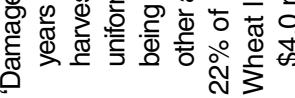
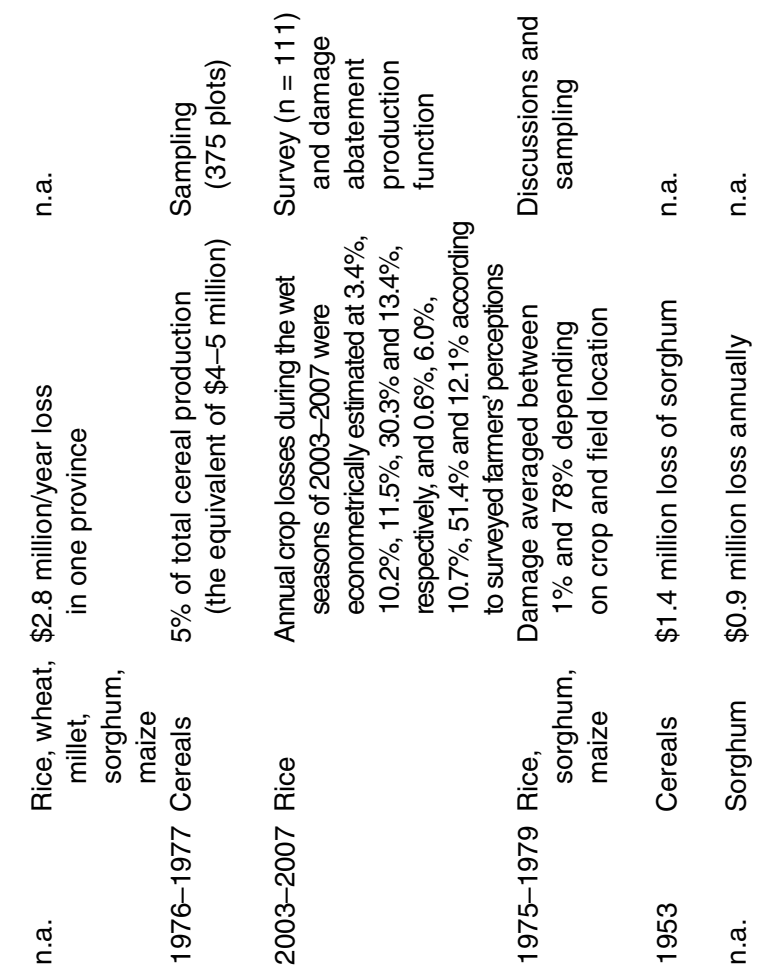

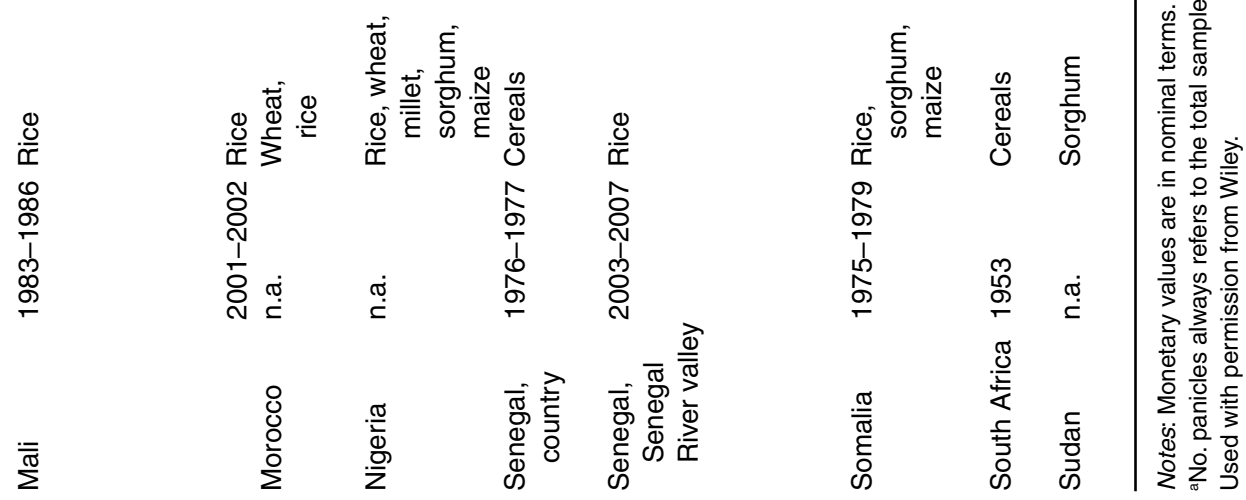
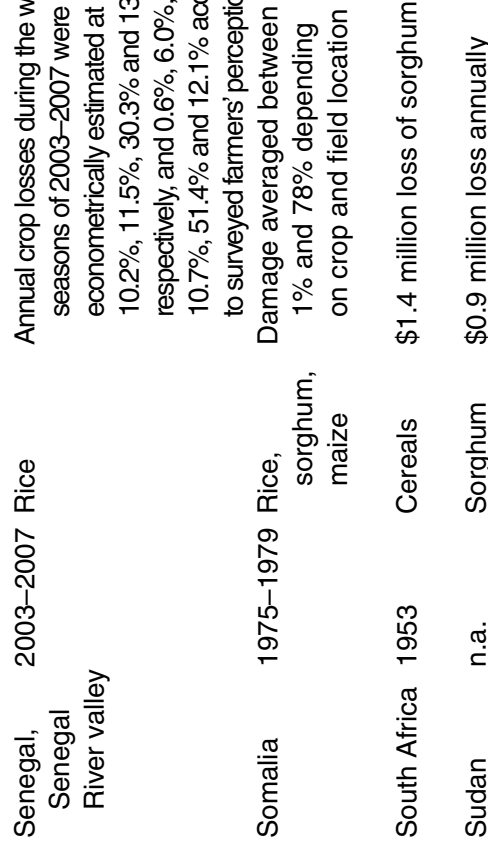

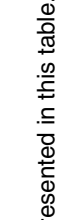

$\frac{0}{\frac{0}{\bar{c}}}$


with bird-resistant characteristics. Religious techniques such as shamanism and fetishes are also still widely adopted in Africa. Protective methods include the use of repellents (chemical substances aimed at deterring birds), protecting fields or nurseries with nets or wires, covering individual heads of ripening crops with grass or cloth, and manual bird-scaring efforts. The latter may consist of a combination of auditory (e.g. noise-making devices, whips, shouting), visual (scarecrows, flags, reflective tape) and physical measures (e.g. throwing rocks or mud).

In general, traditional protective methods such as manual bird scaring, flags and scarecrows can provide satisfactory protection on small-scale, privately owned farms when bird numbers are low. However, when pest bird pressure is elevated, these methods become ineffective (Ruelle and Bruggers, 1982; de Mey et al., 2012). Also, on large-scale, governmental production schemes, these methods are impractical, costly and ineffective (Bruggers, 1980). This suggests that the development of bird populations needs to be monitored and farmers need to be protected against the consequences of massive bird invasions through insurance systems (PINORD, 2009). In particular, there is a need to link bird invasions to climatic factors that influence the development of birds in Africa. Such information can be used to create observatories that monitor the diffusion of birds in order to prevent or anticipate massive bird invasions.

Large-scale, chemical control techniques to reduce population levels of pest birds to non-pest levels are still widely adopted in many African countries (Mullié et al., 1999). Literature suggest these to be inefficient, however, because they do not significantly lower populations due to the pest birds' high reproductive potential and high mobility (Ward, 1979). The frequent inaccessibility of areas in which birds reside also creates a barrier to efficient application of these chemicals. In contrast, lethal control to locally reduce pest bird numbers in the vicinity of important cereal production areas to give temporary relief has been successfully applied. However, the success of this approach varies regionally and by the control method deployed (Bruggers and Jaeger, 1981). It is worth noting that these approaches entail severe environmental hazards when avicides are applied (Mullié et al., 1999).

\section{Conclusion}

Birds, and especially Red-billed Quelea, inflict substantial losses on rice in Africa. Many factors influence the incidence of crop losses, some of which can be controlled by farmers. Accurate bird damage figures are important in order to put the bird problem into perspective and provide useful information for future research, allocation of research funding at the governmental level, and farm management decision making. The available evidence on physical crop losses is somewhat out-dated and suggests an average loss of $15-20 \%$ of total cereal production due to bird damage with substantial spatial and temporal heterogeneity.

Estimates of physical losses, however, underestimate true economic losses as they do not account for costs entailed by the supplyresponse adjustments that farmers make when faced with pests (Chambers et al., 2010). This is supported by farmer surveys in Senegal that suggest that the mere presence of the avian risk is a block to intensification in irrigated rice cultivation (de Mey et al., 2012). Moreover, aside from direct economic impacts, bird damage also has substantial social consequences. On the one hand, farmers who scare birds in the field are socially separated from their family for a long time. On the other hand, traditional bird scaring is frequently undertaken by children who sometimes miss school in doing so, which jeopardizes meeting key education objectives such as universal primary enrolment (de Mey et al., 2012).

Finally, a review of the adopted techniques for controlling bird damage on rice in Africa suggests that mainly traditional, low-cost methods are used. These methods may be adequate under low pest pressure but under high pest pressure they become ineffective. This suggests that research is needed on (i) developing alternative bird-damage control measures that are low cost, environmentally friendly and can be easily adopted by farmers; (ii) predicting massive bird invasions through observatories; and (iii) developing index-based insurance systems that can protect farmers against avian risk. The "public good' nature of bird control - as if one farmer scares birds from his field, these birds are merely displaced to adjacent fields - justifies government intervention. 


\section{References}

Allen, R. (1997) The Grain-eating Birds of Sub-Saharan Africa: Identification, Biology and Management, 1st edn. Natural Resources Institute, Chatham, UK.

Bishop, J., McKay, H., Parrott, D. and Allan, J. (2003) Review of international research literature regarding the effectiveness of auditory bird scaring techniques and potential alternatives. Department for Environment, Food and Rural Affairs, London.

Bruggers, R.L. (1979) Summary of methiocarb trials against pest birds in Senegal. In: Jackson, W.B. (ed.) Wildlife Damage Management, Internet Center for Bird Control Seminars Proceedings. Bowling Green State University, Ohio, pp. 172-184.

Bruggers, R.L. (1980) The situation of grain-eating birds in Somalia. In: Clark, J.P. (ed.) Proceedings of the 9th Vertebrate Pest Conference, Vertebrate Pest Conference Proceedings Collection. University of California, California, pp. 4-16.

Bruggers, R.L. and Jaeger, M.M. (1981) Bird pests and crop protection strategies for cereals of the semiarid African tropics. Paper presented at International Symposium on Sorghum, Pantancheru, India, 2-7 November.

Bruggers, R.L. and Ruelle, P. (1981) Economic impact of pest birds on ripening cereals in Senegal. Protection Ecology 3, 7-16.

Chambers, R.G., Karagiannis, G. and Tzouvelekas, V. (2010) Another look at pesticide productivity and pest damage. American Journal of Agricultural Economics 92, 1401-1419.

De Grazio, J.W. (1978) World bird damage problems. In: Howard, W.E. (ed.) Proceedings of the 8th Vertebrate Pest Conference, Vertebrate Pest Conference Proceedings Collection. University of California, California, pp. 8-24.

de Mey, Y. (2009) Economics of bird control in irrigated rice in the Senegal River valley. MSc thesis, Katholieke Universiteit Leuven, Belgium.

de Mey, Y., Demont, M. and Diagne, M. (2012) Estimating bird damage to rice in Africa: evidence from the Senegal River valley. Journal of Agricultural Economics 63, 175-200.

Elliott, C.C.H. (1979) The harvest time method as a means of avoiding quelea damage to irrigated rice in Chad/Cameroun. Journal of Applied Ecology 16, 23-35.

Elliott, C.C.H. (1989) The pest status of the quelea. In: Bruggers, R.L. and Elliott, C.C.H. (eds) Quelea quelea: Africa's Bird Pest. Oxford University Press, Oxford, pp. 17-34.

FAO (1991) Manuel de Protection des Cultures Contres les Dégâts d'Oiseaux. Food and Agriculture Organization of the United Nations, Dakar, Senegal.

FAO (2001) Economic impacts of transboundary plant pests and animal diseases. In: FAO (ed.) The State of Food and Agriculture 2001. Food and Agriculture Organization of the United Nations, Rome, pp. 198-280.

IRRI, AfricaRice and CIAT (2010) Global Rice Science Partnership (GRiSP). International Rice Research Institute, Manila, Philippines; Africa Rice Center, Cotonou, Benin; and International Center for Tropical Agriculture, Cali, Colombia.

Jackson, J.J. (1973) FAO quelea research in Africa. In: Cones, H.N. and Jackson, W.B. (eds) Wildlife Damage Management, Internet Center for Bird Control Seminars Proceedings. Bowling Green State University, Ohio, pp. 220-222.

Jaeger, M.M. and Erickson, W.A. (1980) Levels of bird damage to sorghum in the Awash basin of Ethiopia and the effects of the control of quelea nesting colonies. In: Clark, J.P. (ed.) Proceedings of the 9th Vertebrate Pest Conference, Vertebrate Pest Conference Proceedings Collection. University of California, California, pp. 20-28.

Jones, P.J. (1989) General aspects of quelea movement. In: Bruggers, R. and Elliott, C.C.H. (eds) Quelea quelea: Africa's Bird Pest. Oxford University Press, Oxford, pp. 102-112.

Luder, R. (1985) Weeds influence Red-Billed Quelea damage to ripening wheat in Tanzania. Journal of Wildlife Management 49, 646-647.

Manikowski, S. (1984) Birds injurious to crops in West Africa. Tropical Pest Management 30, 379-387.

Manikowski, S. and Da Camara-Smeets, M. (1979) Estimating bird damage to sorghum and millet in Chad. Journal of Wildlife Management 43, 540-544.

Mullié, W.C., Diallo, A.O., Gadji, B. and Ndiaye, M.D. (1999) Environmental hazards of mobile ground spraying with cyanophos and fenthion for quelea control in Senegal. Ecotoxicology and Environmental Safety 43, 1-10. 
Oerke, E.-C. (2005) Crop losses to pests. Journal of Agricultural Science 143, 31-43.

Oschadleus, H.D. (2001) Bibliography of the African Quelea Species, 1st edn. Avian Demography Unit, University of Cape Town, Cape Town, South Africa.

PINORD (2009) Study of the Agricultural Risks in the Senegal River Valley. Platforme d'Appui aux Initiatives du Nord, Ross-Bethio, Senegal.

Rodenburg, J., Demont, M. and Sow, A. (2010) Weed control reduces bird damage in irrigated rice. Poster presented at the Second Africa Rice Congress, Bamako, Mali, 22-26 March.

Ruelle, P. and Bruggers, R.L. (1982) Traditional approaches for protecting cereal crops from birds in Africa. In: Marsh, R.E. (ed.) Proceedings of the Tenth Vertebrate Pest Conference, Vertebrate Pest Conference Proceedings Collection. University of California, California, pp. 80-86.

Sidibé, F., Diarra, L.S., Diallo, A.K. and Sylla, C.H. (2003) Caractéristiques et impacts de la lutte antiaviaire dans les zones rizicoles de l'Office du Niger. Rapports techniques. Food and Agriculture Organization of the United Nations and Comité permanent Inter-Etats de Lutte contre la Sécheresse dans le Sahel, Bamako, Mali.

Tracey, J.P. and Saunders, G.R. (2010) A technique to estimate bird damage in wine grapes. Crop Protection $29,435-439$.

Tréca, B. (1977) Le problème des oiseaux d'eau pour la culture du riz au Sénégal. Bulletin de l'Institut Fondamental d'Afrique Noire (IFAN) 39A, 3.

Tréca, B. (1985) Les possibilités de lutte contre les oiseaux d'eau pour protéger les rizières en Afrique de l'Ouest. Journal d'agriculture traditionnelle et de botanique appliquée 32, 191-213.

Tréca, B. (1987) Les dégâts d'oiseaux d'eau sur les rizières aménagées du delta central du Niger au Mali. Journal d'agriculture traditionnelle et de botanique appliquée 34, 153-170.

van Perlo, B. (2002) Collins Illustrated Checklist: Birds of Western \& Central Africa. HarperCollins, London.

Ward, P. (1965) Feeding ecology of the black-faced dioch Quelea quelea in Nigeria. Ibis 107, 326-349.

Ward, P. (1971) Migration patterns of Quelea-quelea in Africa. Ibis 113, 275-297.

Ward, P. (1979) Rational strategies for the control of queleas and other migrant bird pests in Africa. Philosophical Transactions of the Royal Society B: Biological Sciences 287, 289-300.

Weatherhead, P.J., Tinker, S. and Greenwood, H. (1982) Indirect assessment of avian damage to agriculture. Journal of Applied Ecology 19, 773-782. 